\title{
Application of Geodetic Techniques for Antenna Positioning in a Ground Penetrating Radar Method
}

\author{
Ewelina Mazurkiewicz ${ }^{1}$, Eukasz Ortyl $^{2,}{ }^{*}$, and Jerzy Karczewski ${ }^{1}$ \\ ${ }^{1}$ AGH University of Science and Technology, Faculty of Geology, Geophysics and Environmental \\ Protection, A. Mickiewicza Av. 30, 30-059 Krakow, Poland \\ ${ }^{2}$ AGH University of Science and Technology, Faculty of Mining Surveying and Environmental \\ Engineering, A. Mickiewicza Av. 30, 30-059 Krakow, Poland
}

\begin{abstract}
The accuracy of determining the location of detectable subsurface objects is related to the accuracy of the position of georadar traces in a given profile, which in turn depends on the precise assessment of the distance covered by an antenna. During georadar measurements the distance covered by an antenna can be determined with a variety of methods. Recording traces at fixed time intervals is the simplest of them. A method which allows for more precise location of georadar traces is recording them at fixed distance intervals, which can be performed with the use of distance triggers (such as a measuring wheel or a hip chain). The search for methods eliminating these discrepancies can be based on the measurement of spatial coordinates of georadar traces conducted with the use of modern geodetic techniques for 3-D location. These techniques include above all a GNSS satellite system and electronic tachymeters. Application of the above mentioned methods increases the accuracy of space location of georadar traces. The article presents the results of georadar measurements performed with the use of geodetic techniques in the test area of Mydlniki in Krakow. A satellite receiver Leica system 1200 and a electronic tachymeter Leica 1102 TCRA were integrated with the georadar equipment. The accuracy of locating chosen subsurface structures was compared. Key words - Ground Penetrating Radar, geodetic positioning, robotic tachymeter, GNSS system.
\end{abstract}

\section{Introduction}

Geodetic measurement techniques have been successfully applied in many fields of science, for instance geological engineering, geophysics or archaeology, mainly to determine precise coordinates of a characteristic points in a given area (such as the initial and final points of the measuring profiles, a location of a discovered anomaly etc.) [1]. One of the geophysical methods in which the above-mentioned techniques can be employed is the georadar method. A comprehensive introduction to the georadar method can be found in [2-4].

Modern georadar system make it possible to gather huge amounts of data and to conduct surveys of "global character" with profiles of substantial length covering a vast area.

* Corresponding author: ortyl@agh.edu.pl 
Measurements can be conducted with high speed (with georadar antennas mounted on a train or a car). Georadar data obtained in this manner provide additional geospatial information, which, when reduced to a coordinate system, can be combined with other data (gathered for instance in the Geographical Information System) and used to complement thematic maps with information regarding subsurface objects and structures. Typical determination of georadar antenna positions is based solely on measurement performed with the use of an odometer in the form of a wheel or an uncoiling chain. The accuracy of pinpointing the exact location of a recorded trace/route in space is, in this case, very low.

Spatial interpretation of the distribution of the objects registered with the use of georadar methods based only on the data recorded by a georadar, is a significant geometric simplification. A natural and diverse lay of the land over a vast area usually proves impossible to conduct rectilinear and parallel profiling. Georadar surveys are often carried out in the areas where some denivelations occur and the awareness of height differences in the land shaping is vital when the accuracy of positioned objects and the interpretation of the obtained georadar results, are concerned.

Georadar research makes it possible to mark initial and final points of the profiles in the given test field as well as the points where profiles change their direction, and then to measure them with geodetic methods taking into account specific land denivelations. However, such a two-stage survey process is very time consuming, both in terms of gathering geodetic information as well as subsequent post processing of the obtained georadar data. In order to improve the accuracy of the results of georadar profiling, the survey should be based on geodetic techniques using satellite (GNSS) and tachymetric measurements. Georadar data can be gathered simultaneously when a position of the antenna is being determined and recorded, primarily by means of geodetic GNSS satellite techniques or if their application is not possible, by robotic tachymeters of the TCA type capable of automatic target recognition (ATR) and tracking an EDM prism. However, then both devices must be physically integrated with one another, which means that a GNSS receiver or an EDM prism should be mounted directly on a georadar antenna or in its vicinity with a given shift interval.

The accuracy of determining the location with the use of geodetic techniques will depend on the environmental factors and capabilities of a given measuring equipment. Differences in test results will be particularly noticeable while performing GNSS measurements. It should be noted that GNSS measurement can be carried out using the navigational or differential mode.

In the navigational mode the position of the receiver is determined directly on the basis of the signal transmitted by satellites. Due to various factors impairing the signal propagation between a satellite and a receiver, the end result is vitiated with a measurement error (the impact of troposphere, ionosphere and clock errors). Handheld GNSS receivers usually operating in a navigational and occasionally differential mode, use a single frequency, which allows them to determine a given position with the accuracy of no more than $0.5-0.25 \mathrm{~m}$. Therefore, such handheld receivers could be used to indicate an approximate location of georadar measurements

In the differential mode the position of the moving receiver is determined in relation to the Continuously Operating Base Station (a reference one) or to the receivers of the Active Geodetic Network situated over a given point whose coordinates are known in any arbitrary reference system. Thus, in this case far greater accuracy can be achieved.

GNSS receivers for geodetic applications operate in a differential mode using two frequencies, which allows to determine the position of a given object by means of the RealTime Kinematic method with the accuracy of ca. $0.02 \mathrm{~m}(\mathrm{X}, \mathrm{Y})$ ca. $0.03-0.05 \mathrm{~m}(\mathrm{Z})$. As georadar measurement surveys are of dynamic character, application of the RTK method would be the most optimal solution while using a set of GPR-GNSS equipment. 
Similar accuracy can be expected while using electronic homing tachymeters for conducting measurement in a dynamic mode. Lehmann and Green [5] cited the value of ca. $0.04 \mathrm{~m}$ at the prism speed of $1 \mathrm{~m} / \mathrm{s}$.

In both cases it is worth remembering that it is the accuracy determined by stable positioning of the receiver over a given point, which lasts a couple of seconds. However, when georadar measurements are concerned, the accuracy achieved is lower due to uncoordinated movements of georadar antennas.

An additional factor influencing the positioning accuracy of georadar traces is the frequency estimation for a new location computed by a GNSS receiver or a tachymeter.

Modern GNSS geodetic receivers determine a given position with the frequency of 5-20 Hz (some models even with $100 \mathrm{~Hz}$ ), while tachymeters with the frequency of up to $10 \mathrm{~Hz}$. Thus, a new position will appear every $0.1 \mathrm{~s}$ in the case $10 \mathrm{~Hz}$ frequency, and every $0.05 \mathrm{~s}$ if the frequency is $20 \mathrm{~Hz}$.

The article presents the results of georadar measurements performed in the test area of Mydlniki in Krakow. The survey was carried out with the use of georadars of the Swedish company Mala GeoScience (ProEx System and RAMAC/GPR CU II) fitted with shielded antennas of the frequency 100 and $250 \mathrm{MHz}$ and working with various distance triggers (such as a measurement wheel or a hip chain). A satellite receiver Leica system 1200 and a homing tachymeter Leica 1102 TCRA were integrated with the georadar equipment. The accuracy of locating chosen subsurface structures with the use of different positioning methods was compared and evaluated.

\section{Research site description}

The research site is located in Krakow in the district of Bronowice on the terrain that rises slightly in the eastward direction. The test profile is $200 \mathrm{~m}$ long. Figure 1 shows a schematic geological cross-section of the test area.

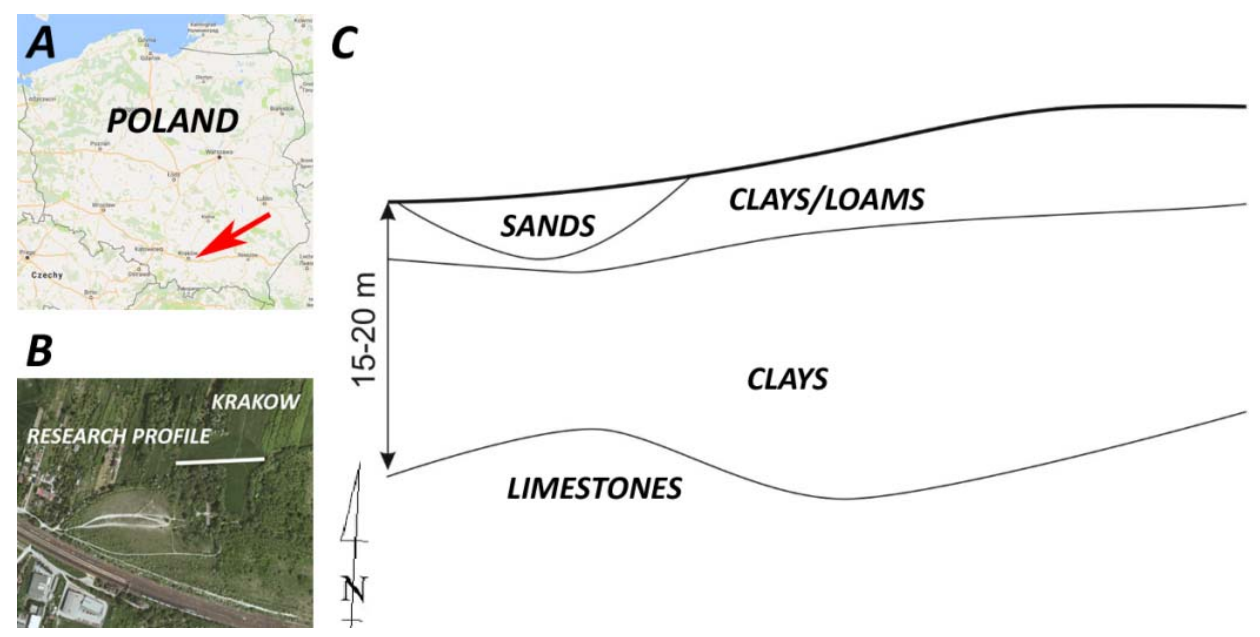

Fig. 1. Localization of the test area in Mydlniki (A, B) and cross-section of probable geological structure of test area the test area in Mydlniki (C by Grzegorz Pacanowski, modified)

According to Kondracki's physico-geographical regionalisation of Poland [6] the test area of Mydlniki is situated in the Kraków-Częstochowa Upland within the Lesser Poland Upland which in turn can be included in the province of Polish Uplands.

Compact structures in the form of clays and loam (very high conductivity ca. $80 \mathrm{mS} / \mathrm{m}$ ) with occasional sand layers of low thickness are found directly in the surface/substratum of 
the investigated area. Miocene silt structures or Jurassic limestones are likely to be situated underneath [7]. However, no opening in the rock bed confirming such geological structure can be found in the immediate vicinity of the test area. The assumption is based on a geological cross-section located at a distance of $2 \mathrm{~km}$ in the eastern section of the research site.

\section{Description of the equipment}

The measurements were performed in the test area of Mydlniki with the use of georadars RAMAC/GPR CUII and ProEx System of the Swedish company Mala Geoscience. More detailed description of both models can be found among others in [8,9]. Antennas of different construction (shielded, unshielded and Rough Terrain Antenna - RTA) as well as different frequencies $(50,100,200,250$ and $500 \mathrm{MHz})$ were used in the conducted survey. This article, due to its size, focuses only on the analysis of the results recorded with the antennas of $100 \mathrm{MHz}$ frequency (see Table 1).

Georadars of Mala Geoscience company enable electromagnetic impulses to be emitted at fixed time or distance intervals, or to be triggered remotely by means of a keyboard. The tests are most often conducted at fixed distance intervals - traces are registered after the antenna travels a given distance. Devices which make such measurements possible are a hip chain and a measurement wheel. The principle they both work on is the same-both of them contain a roller and a device which counts the number of its rotations, which is equivalent to a given unit of distance. A survey conducted with distance triggers makes the operator independent of changes in the antennas' moving speed; moreover, it is more accurate from the measurements carried out at fixed time intervals and much faster than the tests triggered remotely with a keyboard.

However, the measurement of that type is not devoid of flaws. While using a hip chain possible errors of antennas' positioning might result from: pulling of a chain, its slipping over a measurement roller, getting stuck in natural obstacles, etc. Errors in measurement conducted with the use of a measurement wheel might be due to its skidding over the surface of an investigated area. When used on an uneven terrain the wheel erroneously overstates the reading of a covered distance. Geodetic tools should be used in order to eliminate such inaccuracies. Various ways of GPR antennas positioning are shown in Figure 2.
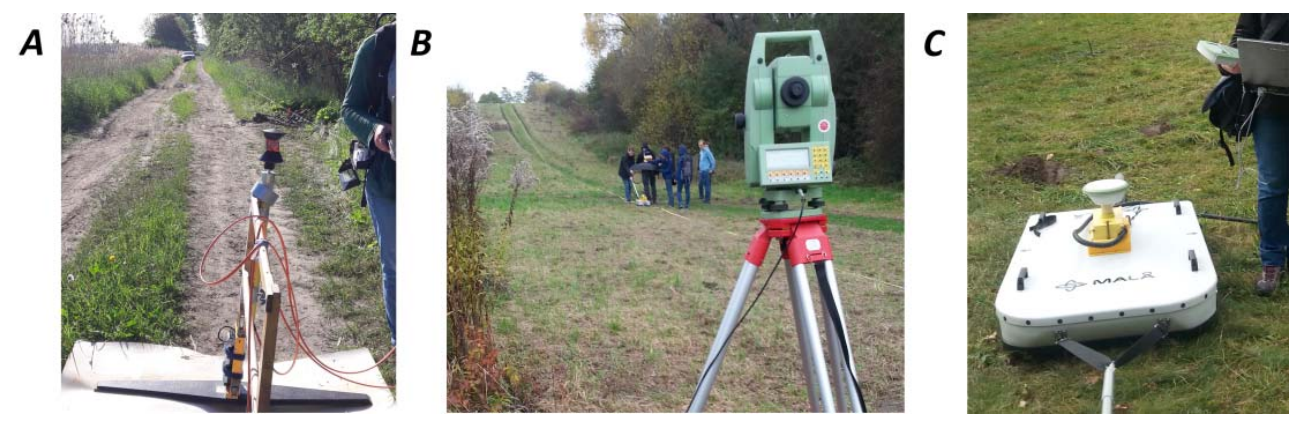

Fig. 2. Positioning systems for GPR antennas: a hip chain (A), a measurement wheel (B) and a robotic tachymeter, a measurement wheel and a GNSS receiver (C)

GPR antenna positioning was conducted with the use of satellite measurements and Leica GPS 1200 Smart Rover receiver operating in the RTK mode as well as the implementation of differential correlations from a single reference station. A robotic tachymeter Leica TCRA $1102+$ was also utilized in the process. The integration of the geodetic instruments with the georadar was carried out by means of a measuring system specially developed by the Geodesy Department at the Faculty of Mining Surveying and Environmental Engineering of the AGH 
University of Science and Technology [10-12]. The receiver and tachymeter were configured to determine and send a new position to the RS232 port using the NMEA protocol with the frequency of $5 \mathrm{~Hz}$ for the receiver and $0.66 \mathrm{~Hz}$ for the tachymeter.

\section{Measurement methodology}

A series of georadar profiles was determined in the test area of Mydlniki with the use of various georadars, different types of antennas and measurement parameters. The following article analyses only selected readings, their list can be seen in Table 1.

Table 1. List of analyzed profiles

\begin{tabular}{|l|c|c|c|c|c|c|}
\hline \multicolumn{1}{|c|}{ GPR model } & $\begin{array}{c}\text { Type } \\
\text { of antenna }\end{array}$ & $\begin{array}{c}\text { Frequency, } \\
{[\mathbf{M H z}]}\end{array}$ & $\begin{array}{c}\text { Distance } \\
\text { between } \\
\text { traces, } \\
{[\mathbf{m}]}\end{array}$ & $\begin{array}{c}\text { Profile } \\
\text { number }\end{array}$ & $\begin{array}{c}\text { Type } \\
\text { of GPR } \\
\text { positioning }\end{array}$ & $\begin{array}{c}\text { Type } \\
\text { of geodetic } \\
\text { positioning }\end{array}$ \\
\hline ProEx & unshielded & 100 & 0.1 & prof004 & hip chain & none \\
\hline RAMAC/GPR CUII & shielded & 100 & 0.1 & prof001 & $\begin{array}{c}\text { measurement } \\
\text { wheel }\end{array}$ & tachymeter \\
\hline RAMAC/GPR CUII & shielded & 100 & 0.1 & prof002 & $\begin{array}{c}\text { measurement } \\
\text { wheel }\end{array}$ & GNSS \\
\hline
\end{tabular}

As the table demonstrates, the survey was carried out with georadar distance triggers-a hip chain and a measurement wheel as well as geodetic positioning techniques - the GPS system and a tachymeter. The next part of this article analyses the accuracy of antenna positioning when the above- mentioned techniques are applied.

\section{Results}

The total length of the measuring profile counted along the surface of the investigated area and determined on the basis of the measurements of direct profile points marked every $2 \mathrm{~m}$, was $187.98 \mathrm{~m}$. However, when measured with a hip chain, the profile appeared to be $187.98 \mathrm{~m}$ and $182.90 \mathrm{~m}$ when the measurements were conducted with the use of a wheel and a tachymeter. The tests involving the application of the wheel and a GNSS receiver recorded the profile length as mere $167.63 \mathrm{~m}$, which indicates the appearance of a significant error, even though the surveys were carried out with the identically calibrated wheel.

It is difficult to notice this data discrepancy while comparing recorded echograms. If positioning was conducted only with the use of a measurement wheel, without any information concerning the total length of a given profile, locating the anomaly placement in the echogram would be significantly imprecise. Therefore, it is vital to implement calibration correlations as the ratio of the profile total length to the profile length as provided by the georadar's gauge. Unfortunately, such a solution has its weaknesses as it does not exclude errors which are non-linear in character (such as a wheel getting stuck at some part of a given profile).

Additional geodetic procedures must be carried out to control the length of the profiles measured along the surface of the investigated area, especially when profiles' topography change. Height differences increase the total length of a profile with regard to its projection (values of the initial and final profile point are insufficient for positioning amendments). The solution based on geodetic positioning systems eliminates this problem.

The echogram (Fig. 3) shows the position of the anomaly between 147 and $168 \mathrm{~m}$ on the profile 1 (Fig. 3B), which in the profile Prof002 is situated between 135 and $153 \mathrm{~m}$ (Fig. 3C). 

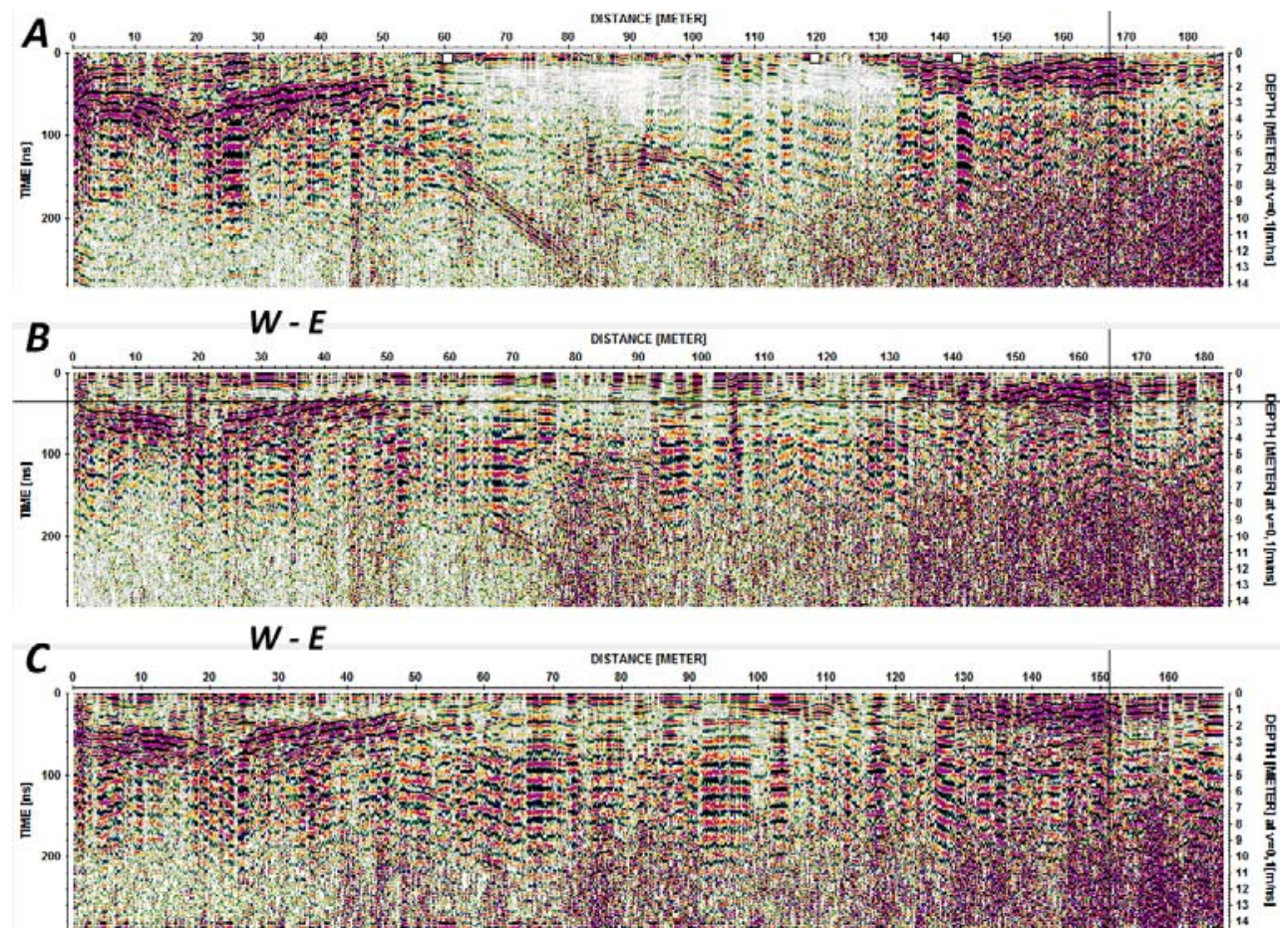

Fig. 3. Prof004 recorded with a hip chain (A), Prof001 recorded with a measurement wheel and robotic tachymeter (B), Prof002 recorded with a measurement wheel and GNSS receiver (C).

Figure 4A shows a comparison of approximated values of geodetic coordinates for both of them in the radargram about 147 and 135 meter of the profiles 1 and 2 respectively.
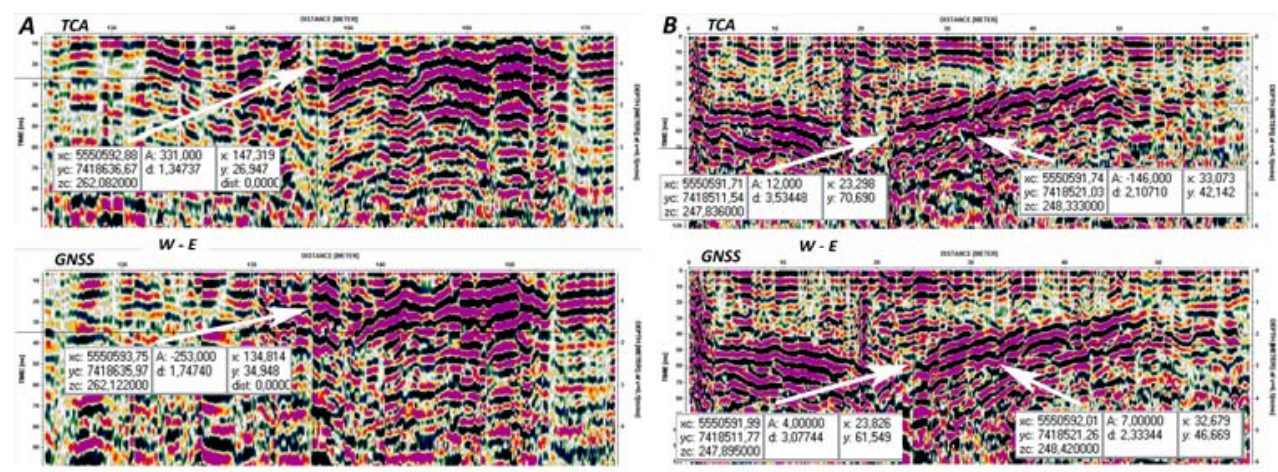

Fig. 4. Summary of geodetic coordinates recorded by robotic tachymeter and GNSS receiver for various anomalies areas: end profile area (A), initial profile area (B)

The results demonstrate correlation at the level of $1 \mathrm{~m}$ without marking any control points, which confirms the efficiency of the positioning carried out with the use of the geodetic techniques. However, when a part of an echogram regarding 168 and $153 \mathrm{~m}$ of the profiles was analyzed, coordinate discrepancies increased to about $3 \mathrm{~m}$. Consequently, the analysis of the obtained geodetic data was conducted.

Figure 5 depicts changes in the accuracy of the geodetic data for the TCA (Fig. 5A) and GNSS (Fig. 5B) by means of evaluating the diagram of plane coordinates and heights/altitudes determined by both of the devices during the survey. 

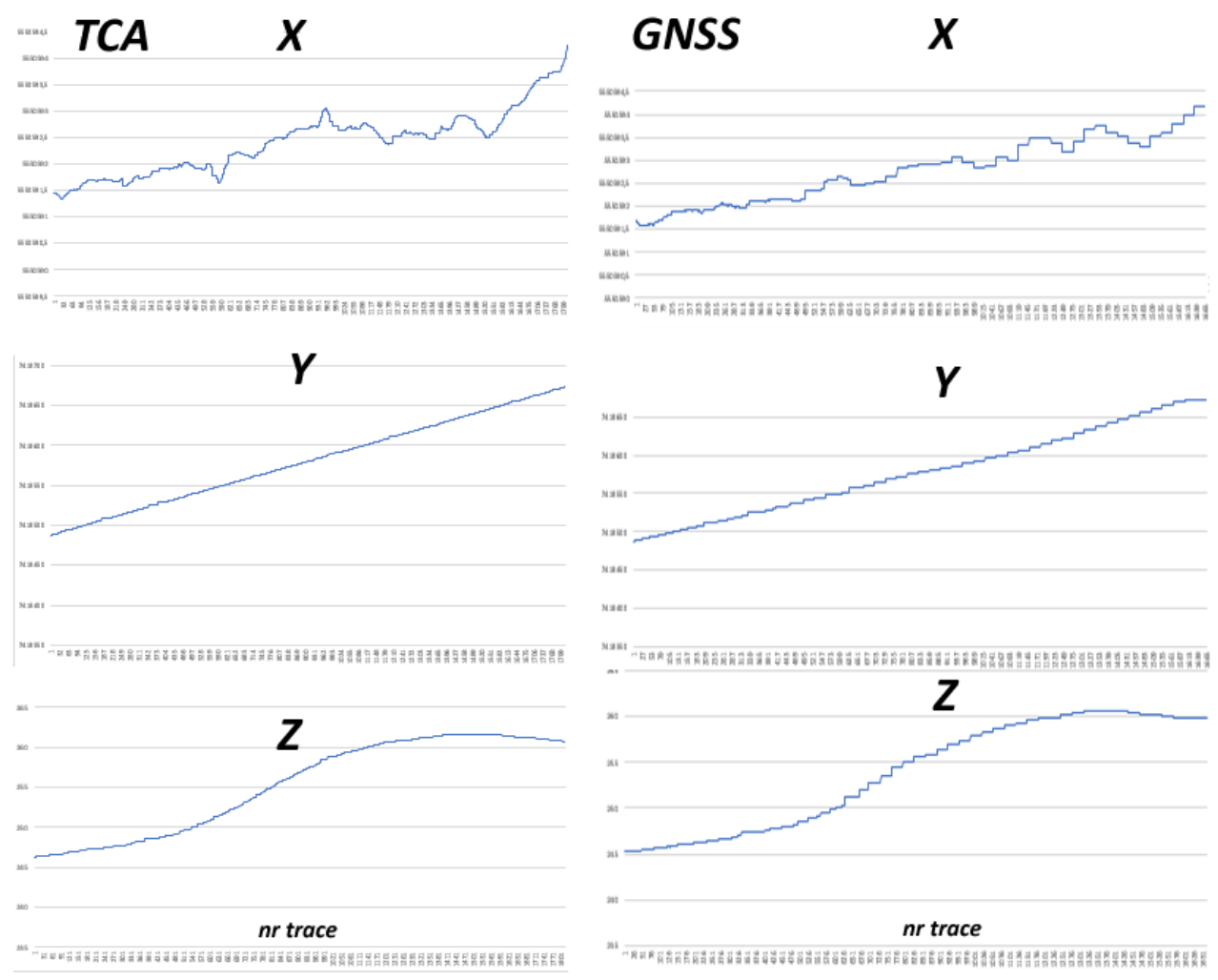

Fig. 5. Summary of geodetic coordinates obtained by robotic tachymeter and GNNS receiver on analyzed measurement profiles

In the case of GNSS receiver, a clear decline in accuracy of the determined positions starts at $1 / 3$ of the profile (stepped character of plane coordinates and altitude data), which differs from the values recorded by the TCA along the whole profile. The area where the GNSS and TCA data correspond is located at $1 / 3$ of the profile. Figure 4B demonstrates correlation of spatial positioning results at the level of $0.1-0.3 \mathrm{~m}$.

\section{Conclusions}

While conducting georadar research certain limitations of various positioning techniques regarding the process of subsequent placement of the recorded anomalies, should be taken into account.

In the analysed case (Fig. 3A) the measurement conducted with the use of a hip chain proved to be reliable as far as the profile length was concerned, but at the same time insufficient to determine spatial position of the anomaly. Consequently, performing additional geodetic procedures would be required, especially in order to determine the altitude coordinate.

The profile recorded by means of the measurement wheel (Fig. 3C) turned out to be erroneous even though it seemed to be visually counterintuitive as may be the case when a hip chained is used.

The article pointed out the advantages of positioning with the use of the geodetic systems. Even though they decrease the accuracy of the wheel, they situate an anomaly correctly.

However, it has been demonstrated that even such data should not be exempt from criticism. Verification of the obtained information especially when gathered by means of the GNSS is highly recommended. During the survey carried out in the test field of Mydlniki 
in perfect visibility, the GNSS system failed for some unexplainable reasons decreasing the positioning accuracy in the final part of the echograms (from $60 \mathrm{~m}$ ).

In the area where the data from the GNSS system was recorded with high accuracy, such a problem does not occur. In such conditions high positioning correlation $(0.1-0.3 \mathrm{~m})$ to the results obtained by means of the TCA method, which is highly reliable but at the same more demanding, can be observed.

\section{Acknowledgements}

The research has been funded from the appropriations received from the NCBR (the National Centre for Research and Development) and GDDKiA (the General Director for National Roads and Motorways) and as part of the project and the competition for the RID (Development of Road Innovation) Project "Modern methods of subsoil identification in road engineering" with the acronym OT1-1E/PIG-AGH-PW.

\section{References}

1. S. Porzucek, W. Matwij, 17th International Multidisciplinary Scientific Geoconference: Science and Technologies in Geology, Exploration and Mining, Conf. Proc. 17, 57-64 (2017)

2. H. M. Jol, Ground penetrating radar: theory and applications (Elsevier 2009)

3. J. Karczewski, Ł. Ortyl, M. Pasternak, Zarys metody georadarowej (UWND AGH, Kraków, 2011)

4. M. Łyskowski, E. Mazurek, J. Ziętek, Journal of Cave and Karst Studies, 76, 184-190 (2014)

5. F. Lehmann, A.G. Green, Geophysics, 64, 719-731 (1999)

6. J. Kondracki, Geografia Regionalna Polski (Wyd. Naukowe PWN, Warszawa, 2002)

7. J. Rutkowski, Szczegółowa mapa geologiczna Polski w skali 1:50000, arkusz 973Kraków (1989)

8. A. Benedetto, L. Pajewski., ed., Civil Engineering Applications of Ground Penetrating Radar (Springer, 2015)

9. M. Pasternak (red.), Radarowa penetracja gruntu (Wyd. Komunikacji i Łączności, Warszawa, 2015)

10. J. Gocał, Ł. Ortyl, M. Sołtys, in: Geodesy, photogrammetry and monitoring of environment, 5-14 (2006)

11. Ł. Ortyl, A. Bałut, [in:] Geodesy, photogrammetry and monitoring of environment, 27-44 (2006)

12. Ł. Ortyl, T. Owerko, Zeszyty Naukowe Politechniki Śląskiej, 278, 335-352 (2007) 